I Universidade de São Paulo (USP), Núcleo de Sociologia da Cultura,

São Paulo, SP, Brasil

dimpinhas@gmail.com

https://orcid.org/oooo-00oI-7907-9943

Dimitri Pinheiro'

\title{
ANOS REBELDES E A ABERTURA DA TELEFICÇÃO'
}

Existe uma contradição na televisão brasileira que faz com que o telejornal seja mais mentiroso do que a novela. Há mais verdade na novela - que é ficção - que no telejornal, que seria a informação! Principalmente na Globo, que foi quem deu o formato de televisão que temos hoje. [...] Foi, por exemplo, uma minissérie - Os Anos Rebeldes - que trouxe para a televisão o tema da guerrilha, que era um tabu no telejornalismo. Todo telejornalismo da Rede Globo era a favor do Collor. [...] Assim, pelo melodrama, pela ficção essas questões sociais e políticas entram na televisão. Isso porque, ao receber a função de integrar a nacionalidade - hoje um pouco transformada -, a televisão, e principalmente o telejornalismo que fazia o discurso da integração nacional, precisava mostrar certas coisas e esconder outras. Isso produz uma polarização tão grande com a realidade que a ficção acaba servindo de mediação e muitas vezes é porta de entrada para coisas que estavam escondidas. [...] Porque a televisão, por intermédio da novela, dá visibilidade e isto é condição para existir no Brasil. Aquilo que não aparece na TV, a sociedade ignora. Paradoxalmente, ao dar visibilidade, a novela deu também cidadania

(Bucci, I997)

Certamente Anos rebeldes está entre as mais celebradas produções televisivas brasileiras, especialmente da Rede Globo. Essa posição constitui um efeito tangível da lógica promocional imposta pela típica sinergia entre as diferentes instâncias da própria indústria cultural. Seria ingenuidade, no entanto, desconhecer a participação da própria atividade acadêmica nesse processo. Mesmo quando assume as roupagens de um juízo depreciativo e acusatório - mediante tortuosas operações simbólicas que guardam muita semelhança com a de- 
negação psíquica -, a celebração que envolve a minissérie também vem embalando a realização de uma fortuna considerável de estudos. Tal fenômeno não deixa de ser um tanto surpreendente, ainda mais tendo em vista a relativa desvalorização dos bens simbólicos associados ao polo ampliado de produção cultural na hierarquia dos objetos acadêmicos. ${ }^{2}$

Para a pesquisa sociológica sobre a teleficção ${ }^{3}$ produzida no Brasil, Anos rebeldes constitui marco importante numa periodização orientada por balizas internas e externas ao domínio televisivo: a Queda do Muro de Berlim e a Guerra do Golfo; a vitória de Fernando Collor nas eleições presidenciais de I989, o movimento dos "caras pintadas", o processo de impeachment e a renúncia do presidente da República; a edição abertamente tendenciosa do último debate entre Lula e Collor promovido pela Rede Globo e a derrocada de Armando Costa da direção da Central Globo de Jornalismo; a minissérie como a primeira vez em que a emissora ousa abordar diretamente o tema ditadura militar na frente de produção teleficcional; entre outras possíveis. A concatenação dessas balizas evita que a análise incorra nos riscos simétricos de impor um enquadramento demasiado generalizador ao objeto - isto é, supor uma correspondência imediata entre os eventos da conjuntura e a produção dos programas - ou de simples reiteração dos marcos estabelecidos pela narrativa dominante entre os profissionais. Como formulou sinteticamente Fredric Jameson (I988: I79, tradução livre),

o "período" em questão é compreendido não como algum estilo partilhado ou modo de pensar e agir onipresente e uniforme, mas como o compartilhamento de uma situação objetiva, para o qual todo um conjunto de respostas variadas e inovações criativas é, então, possível, mas sempre dentro dos limites estruturais dessa situação. ${ }^{4}$

Não que as produções da emissora tenham evitado completamente abordar os anos do regime militar. De fato, quando adotamos as minisséries como ponto de observação, fica patente que a Rede Globo se voltou regularmente para aqueles anos, mas, sobretudo, de modo indireto, ou seja, mediante o que Ismail Xavier, fazendo referência a outra formulação de Jameson (por sua vez, inspirada na "figura" auerbachiana), chamou de estratégias de alusão. ${ }^{5}$ Dessa perspectiva, Anos rebeldes viabiliza um corte transversal, permitindo à análise transitar dos registros mais rarefeitos (por exemplo, os acontecimentos da "conjuntura mundial") aos densamente substantivos - tomadas de posição inscritas especialmente na fatura das obras (Bourdieu, 2005).

À medida que tenta compatibilizar essas diferentes coordenadas de atenção, o encaminhamento da análise desenvolvida aqui realiza os seguintes movimentos: primeiro, delineia telegraficamente os fatores gerais (sociais e políticos) que condicionaram o esforço despendido pela Rede Globo no sentido de diversificar seus formatos teleficcionais; em seguida, pontua algumas das circunstâncias mais importantes na realização de Anos rebeldes; o terceiro movi- 
mento reconstitui sumariamente o enredo, enfatizando uma vertente de suas tramas; à guisa de conclusão, alinhava um comentário, bem como um esboço de síntese sobre os sentidos assumidos pelo programa e, reflexivamente, pela própria análise sociológica da indústria cultural.

\section{CONDICIONANTES}

Entre I977 e I982, a Rede Globo realiza experiências envolvendo a produção e a exibição de programas com formatos alternativos às telenovelas. Primeiro testa os chamados seriados e, posteriormente, encampa as extremamente onerosas minisséries, cuja produção se rotiniza a partir de então. De I982, quando a primeira minissérie é exibida, a I985, ano em que a emissora realiza adaptações de romances consagrados - Tenda dos milagres (Jorge Amado), 0 tempo e o vento (Érico Verissimo) e Grande sertão: veredas (João Guimarães Rosa) - como parte das comemorações pelos seus 20 anos, I4 minisséries seriam veiculadas. Diferente da telenovela e, em menor medida, do seriado, a minissérie não se enquadra nos mecanismos rotineiros de financiamento das produções no âmbito do sistema televisivo comercial brasileiro, sobretudo em função da curta duração, inviabilizando a reiteração de personagens e cenários, e, por sua vez, reduzindo as possibilidades de diluir custos ao longo de meses de exibição, bem como a margem de retorno obtido em termos de verbas publicitárias e merchandising. ${ }^{6}$ Não por acaso viabilizada em um momento no qual a emissora detinha liderança absoluta nas "escalas de audiência" - favorecida pelo fechamento progressivo das principais concorrentes (a Excelsior em I970 e a Tupi justamente em I980) - e açambarcava o maior naco das verbas publicitárias estatais e privadas, a aposta pode ser explicada como uma tomada de posição com dupla interface.

No front político, sinaliza um movimento de distanciamento da emissora em relação ao regime militar então nos estertores. Como a própria reviravolta com relação aos formatos indica, não se tratou de um processo uniforme e unívoco. Isso fica evidente sobretudo quando se consideram as diferentes lógicas, bem como os diversos ritmos imperantes nas principais frentes de produção (ou "polos de legitimidade") da televisão: na terminologia nativa, "teledramaturgia" e "telejornalismo".7 Os avanços e recuos na frente de teleficção - sempre sujeitos às marchas e contramarchas da conjuntura - podem ser flagrados ao menos desde 1968 seja no comprometimento das dez horas da noite com a veiculação de telenovelas extremamente arrojadas estética e politicamente, seja na tentativa de reformar a grade de programas - transferindo para o horário das oito as telenovelas veiculadas às dez - tolhida por veto unilateral da Censura Federal à primeira versão de Roque santeiro (I975), ou, ainda, no mesmo ano, com o estabelecimento do horário das seis (visando corresponder ao viés paternalista também exigido pelo regime militar) para a veiculação de adaptações de obras associadas ao romantismo literário brasileiro como Helena (Machado de Assis). ${ }^{8}$ 
Já no telejornalismo aquele movimento seria ainda mais complexo porque se concluiria apenas na esteira da campanha pelas eleições diretas em I 984 , com a Rede Globo sucessivamente abandonando o bloco de sustentação ao regime militar, se colocando na retaguarda da luta pela redemocratização política, ocupando a posição de fiel da balança na candidatura de Tancredo Neves à presidência da República e assumindo virtualmente o cockpit no governo do presidente José Sarney. ${ }^{9}$ Ao contrário do que se observa na teleficção, entretanto, no telejornalismo o movimento seria concomitante a um acirramento da censura interna que reduziu drasticamente não só a possibilidade de veicular perspectiva diversa daquela imposta pelo editorial, como tolheu a margem de experimentação formal. ${ }^{\text {1 }}$

No front do público, a experimentação se insere numa estratégia de programação que visava atingir um segmento específico de telespectadores: pessoas do sexo masculino, com maior nível de renda e escolaridade, possibilidades mais amplas de lazer e relativamente impacientes diante da cantilena situacionista. A tentativa de diversificação na frente de teleficção poderia, então, ser tomada como uma aposta na segmentação - embora ainda bastante embrionária - do mercado de comunicação eletrônica, indicando, por sua vez, uma diferenciação da estrutura social brasileira também passível de ser compreendida à luz das transformações mais gerais ocorridas nesse período. ${ }^{\text {I }}$

Tampouco constitui coincidência fortuita o fato de que justamente em I 985 - outro marco fundamental da conjuntura nacional - o formato minissérie, contando com núcleos de produção plenamente estabelecidos, exibições regulares e bastante prestígio no interior da Rede Globo, tenha sido objeto de outro projeto de renovação: a "Casa de Criação Janete Clair". Idealizada por Dias Gomes, a Casa constituiria um espaço de troca entre os profissionais, de treinamento e de revelação de novos autores, mas o projeto seria inviabilizado precocemente. Ao menos parte das propostas, em especial os "retratos de época" e a incorporação de procedimentos coletivos de produção, seria levada adiante por minisséries. ${ }^{12}$

A proposta dos retratos de época previu inicialmente a realização de duas minisséries: uma centrada nos anos de I950, Anos dourados (I986) e outra em I960, Anos rebeldes. ${ }^{\mathrm{I} 3}$ Esta última só seria realizada em 1992 e também sob a autoria de Gilberto Braga - mudança reveladora, uma vez que a indicação original da emissora foi a de Gianfrancesco Guarnieri. O próprio Gilberto Braga (20I0: 24) atribui a escalação a seu perfil político: considerando-se um "alienado" notório durante a juventude, ele representaria menor risco para a emissora do que Dias Gomes ao tratar do tema "ditadura".

Tal escolha foi diretamente atribuída a José Bonifácio de Oliveira Sobrinho, o Boni (nessa ocasião vice-presidente de operações da Rede Globo), mas envolveu indiretamente Roberto Marinho, que encarregou o jornalista Cláudio Mello e Souza de ler o roteiro e emitir o "parecer" pela reformulação do décimo capítulo 
ao I $4^{\circ}$, porque, ao retratar o período que vai de dezembro de I 968 ao AI-5, estava "carregando demais nas tintas políticas" (Braga, 2010: 29). O conjunto de medidas não pode ser dissociado das tensões acumuladas durante os vários episódios de censura interna, ao menos desde os cortes em O pagador de promessas (I988), ${ }^{\mathrm{I} 4}$ passando pelos protestos internos desencadeados pelos vários lances de apoio aberto ou velado da emissora à candidatura de Fernando Collor e culminando com a edição do último debate antes das eleições de I989. Essas tensões iluminam, retrospectivamente, o fechamento da Casa de Criação e, prospectivamente, o destino dos produtores associados à tradição populista de esquerda, que perdem espaço na Rede Globo a partir da segunda metade da década de I980. ${ }^{15}$

Ao mesmo tempo em que alija esses profissionais ostensivamente inquietos (os autores especialmente) do trabalho com telenovela - livrando seu produto mais rentável de riscos tidos como dispensáveis -, a cúpula da empresa os mantém em seus quadros, evitando, com isso, desfalques que eventualmente poderiam fortalecer a concorrência. Nessa estratégia, as escalações esporádicas para a realização de minisséries desempenharam papel auxiliar, funcionando como uma espécie de reserva mutuamente prestigiosa, embora, por vezes, significando uma faca de dois gumes para profissionais que precisem de um maior volume de trabalhos para sobreviver financeiramente. ${ }^{16}$

Por se tratar de um produto finalizado antes de sua exibição, de menor duração, estruturalmente mais coeso e que usualmente concede maior tempo de preparação para os profissionais envolvidos em sua produção - motivos que elucidam o interesse que desperta no interior do próprio meio televisivo -, o formato não se mostra tão sujeito quanto à telenovela às pressões econômicas diretas (sob a forma do merchandising) e indiretas (via índice de audiência). ${ }^{17} \mathrm{Em}$ função desse conjunto de características, as minisséries se prestam melhor às pretensões autorais dos profissionais - roteiristas e diretores em especial - desejosos de expressar perspectivas pessoais sobre a teleficção e o mundo, deixando entrever de modo mais explícito o "pendor pedagógico tanto do enredo como dos diálogos, permitindo uma apresentação cabal e explícita da visão de mundo que rege as lições morais da indústria cultural brasileira" (Xavier, 2003: I44).

Se a telenovela constitui o centro axial de sustentação comercial da televisão, a minissérie configura, principalmente no período que circunscreve Anos rebeldes, uma zona de prestígio depurado para os produtores. O significado prestigioso da minissérie, entretanto, não se encerra aí. Também ilumina a importância que a legitimidade cultural - programação ou audiência de "qualidade" na terminologia nativa - angariada por esse tipo de programa representa para uma instância da indústria cultural que se encontra perenemente ameaçada pelo descrédito simbólico, esteja este sob a expressão mais indireta do arbitrário cultural dominante (as campanhas contra a "baixaria") ou mediante a forma mais direta dos reclamos por cumprimento de sua função social (a agenda voltada para a "democratização" dos meios de comunicação). 


\section{CIRCUNSTÂNCIAS ${ }^{18}$}

Anos rebeldes foi exibida pela Rede Globo entre julho e agosto de I992, coincidindo, portanto, com um momento decisivo no processo de democratização política do país: o agravamento da instabilidade política que levaria à renúncia de Fernando Collor, então o primeiro presidente eleito diretamente desde I96o. Como já mencionado, foi também a primeira incursão explícita na teleficção da emissora pelo tema ditadura militar brasileira, abrangendo diageticamente um período que vai do momento imediatamente anterior ao golpe de I964 à anistia em I979. Explorada pelas diferentes frentes da indústria cultural, a concomitância catalisada na minissérie ensejou o que parcela da literatura chamou de "fusão da memória" relativa aos anos ig6o e a campanha "Fora Collor" (Kornis, 2000: I I5-I I6), convertendo Anos rebeldes não só em marco da teleficção brasileira, mas, ironicamente, numa força social com algum peso na esfera pública.

A escalação para a autoria da minissérie (a segunda em sua carreira) significou mais uma premiação simbólica conferida pela Rede Globo aos serviços prestados por Gilberto Braga, que vinha de dois sucessos consecutivos Vale tudo (I988-I989) e, apesar de um "tropeço" inicial, O dono do mundo (I99 I I992) I9 - nas escalas de audiência no horário das oito horas da noite. O trajeto percorrido por ele expressa muito bem os principais fatores que incidem no recrutamento e na carreira profissional de um "autor" de televisão: domínio da cultura letrada e treinamento pregresso - condição necessária tendo em vista a demanda compulsória pelo exercício da criatividade - em alguma instância da indústria cultural.

O ingresso de Gilberto Braga na emissora se deu pelo contato com Domingos de Oliveira, um dos responsáveis pelo programa de unitários Caso Especial. Por intermédio do diretor, o egresso da Aliança Francesa e então crítico teatral de O Globo seria escalado para escrever os roteiros de cinco programas entre I973 e I974, o primeiro deles adaptado do romance A dama das camélias (Alexandre Dumas Filho). Com a perspectiva de remanejamento de Lauro César Muniz para escrever telenovelas das oito horas, o iniciante seria convidado para ocupar a vaga deixada na faixa das sete, inicialmente como colaborador e posteriormente assumindo Corrida do ouro (1974) sob supervisão informal de Janete Clair. Certamente a experiência com adaptações motivou Daniel Filho a convidá-lo para a equipe responsável por implementar, em I975, telenovelas às seis horas - novo horário inteiramente dedicado aos romances brasileiros (especialmente os pertencentes ao romantismo literário) -, obtendo seu maior sucesso nas escalas de audiência em I976, com Escrava Isaura (Bernardo Guimarães). Nesse ínterim, quando Janete Clair vai cobrir a lacuna na faixa das oito causada pela proibição de Roque santeiro, ela o escolhe para continuar Bravo! (I975-I976), exibida às sete. A eleição pela mais importante autora da emissora lhe conferiria notoriedade e a partir daí ele desenvolve uma careira ascen- 
dente nos quadros da Rede Globo. Ao ocupar o topo na hierarquia de poder espiritual, o autor impôs à minissérie a chave melodramática à la Balzac que lhe é característica ${ }^{20}$ e definiu o centro nodal da narrativa: o romance entre uma "garota individualista", interpretada por Malu Mader, e um "rapaz idealis ta", representado por Cássio Gabus Mendes, sob o "pano de fundo" da ditadura militar - ator e atriz já haviam se notabilizado em papéis de mocinho e mocinha nas telenovelas do autor (Braga, 20ıo).

Dennis Carvalho para a "direção geral" - o topo na hierarquia de poder temporal - foi outra escalação diretamente associada a Gilberto Braga. ${ }^{2 \mathrm{I}} \mathrm{Tal}$ qual o trajeto do autor, o de Dennis Carvalho revela tão bem quanto os principais fatores incidentes no recrutamento e na carreira de diretor em televisão: o sexo (masculino), a raça (branca) e a socialização primária no meio profissional, seja por experiência familiar, seja pelo trabalho precoce. Ainda adolescente iniciou como ator na adaptação de Oliver Twist (Charles Dickens), veiculada em I964 pela TV Tupi, onde seguiria carreira aproximando-se de Walter Avancini (não por acaso, ele próprio um ex-ator mirim), que lhe teria despertado o interesse por direção. Após sucesso nas escalas de audiência como vilão em Ídolos de pano (I974), aceita, sob promessa de posterior iniciação na direção, convite de Boni para se transferir para a Rede Globo. Na emissora, se aproxima de Daniel Filho, intercalando o aprendizado na função e papéis como galã (posição extremamente racializada). A partir de Sem lenço, sem documento (I977-I978), exibida às sete horas, assume formalmente a direção sob o comando de Régis Cardoso. Ainda nesse ano, é convidado a dirigir sozinho o último episódio de Ciranda cirandinha. O entrosamento com Gilberto Braga vinha de uma longa série de trabalhos, entre os quais Vale tudo e O dono do mundo.

Despertado para a carreira pela figura de Walter Avancini, a partir de sua inserção na Rede Globo o futuro diretor foi diretamente influenciado por Daniel Filho, razão pela qual pode ser considerado um seguidor da modernização do melodrama - isto é, a introdução de maior "coeficiente de realismo" às tramas (Xavier, 2003: 93; I43-I44) - que notabilizou o então chefe do Departamento de Telenovelas. Todavia, Dennis Carvalho não deixou de expressar de maneira mais discreta em seus trabalhos os arroubos de experimentação formal, bem como o recurso a "estratégias de alusão" que tornaram marcante a fatura de Avancini. Salvo engano, essa convergência de influências também pode ser conferida na minissérie.

Como já era de esperar, durante a produção da minissérie Boni determinou a modificação de quatro capítulos já gravados (I I, I 2, I 3 e I4) requentando a justificativa de que enfatizavam excessivamente aspectos políticos em detrimento da trama amorosa entre João Alfredo e Maria Lúcia, sob a alegação adicional de que isso provocaria inevitável desinteresse do público (verdadeiro deus ex machina para os produtores e, a fortiori, perante a cúpula de executivos da Rede Globo). Essas interferências acarretaram atraso, e as gravações só foram 
concluídas quando Anos rebeldes já estava sendo exibida, algo inusual para um formato que, ao contrário da telenovela, se caracterizaria por constituir "obra fechada". Outra prática de censura, embora menos ostensiva, foi o atraso deliberado no horário de exibição quando os episódios abordaram a decretação do AI-5 (Kornis, 2000: I I 2).

Em consequência mais ou menos direta dessas circunstâncias de produção, a história do período se transfigura sob chave moral e individualizada, similar em diversos momentos aos moldes do "drama doméstico" (Kornis, 2000: I09). Não por acaso, a narrativa praticamente reduz os trabalhadores rurais e urbanos a figurantes, concentrando todo o foco de atenção na luta deflagrada pelo setor radicalizado da pequena e da alta burguesia, contra o regime militar e em defesa de um ideal difuso de justiça social (figurado sobretudo por referências à questão agrária).

\section{ENREDO 22}

Os letreiros exibidos em diversos momentos da narrativa explicitam uma organização em três fases: "março de i964: Os anos inocentes", "abril de ig66: Os anos rebeldes", "[dezembro de ig68] Os anos de chumbo", mais um epílogo que remete a I979 e à anistia. Não obstante, parece possível localizar inflexões associadas aos movimentos - ora de aproximação, ora de afastamento - do casal principal por conta das opções de João Alfredo ante a conjuntura política, bem como pela inserção de painéis documentais realizados com a participação do cineasta Silvio Tendler.

A minissérie se inicia com a recapitulação do primeiro contato entre João e Maria Lúcia anteriormente ao golpe civil-militar de I964. Simultaneamente também é apresentado o grupo de rapazes cuja formação (em seu último ano no Colégio Pedro II) e posterior desagregação serão acompanhadas até o final do enredo: Edgar (Marcelo Serrado), Galeno (Pedro Cardoso) e Waldir (André Pimentel). Em função da coerência interna deste artigo não é possível nem conveniente reconstituir em detalhe a narrativa e tampouco reproduzir o minucioso sistema de notação necessário para uma análise da minissérie em sua complexidade. A análise prioriza, assim, as tramas que se desdobram a partir de uma personagem que originalmente não integra a turma de amigos, mas, pouco a pouco, ganha a posição de protagonista: a personagem Heloísa (Cláudia Abreu).

Do ponto de vista formal, Heloísa permite um equacionamento ótimo da economia narrativa, que, a um só tempo, eleva a voltagem melodramática, concatena a pedagogia política propagandeada pelos profissionais e aciona a estratégia de alusão indicada no início desta exposição. A personagem põe em cena Fábio Andrade Brito (José Wilker), pai de Heloísa e dono do poderoso grupo empresarial homônimo. Intermediado por Maria Lúcia, sua colega do curso de francês, o contato com a turma do Colégio Pedro II - em especial as sequências pautadas pelos diálogos com João Alfredo - desencadeia a progressiva 
conscientização política que conduz a filha do magnata - e, figurativamente, o público telespectador - ao rechaço da vida burguesa (cujo marco é a ruptura com o casamento de conveniências), à radicalização e ao posterior engajamento na luta armada.

A conversão de Heloísa em heroína é simétrica à caracterização de Fábio como vilão, condensando, com isso, todas as tensões da minissérie (sexuais, geracionais, raciais, sociais, políticas e culturais) na esfera íntima. O conflito entre filha e pai caracteriza um embate do bem contra o mal. Personificação do regime político opressor, o magnata é apresentado pela narrativa como pai ausente, marido infiel, racista, capitalista selvagem, fazendeiro escravagista, apoiador de primeira hora do golpe civil-militar, presuntivamente patrocinador dos aparelhos clandestinos de violência estatal, e, suprema vilania, responsável indireto pelo assassinato da própria filha por forças da repressão.

\section{COMENTÁRIO}

Dada a usual suspeição política que recai sobre a Rede Globo e seus programas, Anos rebeldes dificilmente poderia ser mais desconcertante. Põe em tela uma representação da ditadura militar em que os mocinhos são guerrilheiros que sequestram um embaixador suíço para libertar presos políticos, e o magnata, dono de um conglomerado empresarial, figura como vilão, constituindo uma mostra bem-acabada do potencial "democrático" do melodrama. ${ }^{23}$ Conforme afirma Ismail Xavier, Anos rebeldes configura a reconstituição audiovisual mais bem sucedida acerca do período, sobretudo se comparada às melhores realizações da cinematografia no país até então. Não obstante, ele interpõe a ressalva de que apesar de ter aprendido a se comunicar com o seu público sobre os assuntos relativos à vida privada, a rede de televisão ainda se voltaria para a política

com uma preocupação autoapologética que conduz à idealização costumeira, velando seus interesses em jogo no processo econômico e político, e apresentando apenas o que parece politicamente correto em sua performance como instância maior de administração da consciência pública. Esse é claramente o caso de Anos rebeldes, em que a Rede Globo conta a história dos anos de ditadura sem mencionar o papel e a cumplicidade dos meios de comunicação, incluindo o seu, no processo de controle político e social no período (Xavier, 2003: I60).

Não parece pertinente rejeitar o juízo informado daquele que, seguramente, está entre os mais reconhecidos estudiosos seja do cinema em particular, seja da crítica cultural de modo geral. Cabem, entretanto, algumas qualificações. A apreciação é analiticamente rentável, sobretudo, para a posição oficiosa do conglomerado mais dinâmico do polo ampliado de produção cultural no país. Este, entretanto, nem sempre consegue "administrar a consciência" dos seus criadores completamente, mormente tendo em vista processos de realização que envolvem redes de cooperação tão vastas e complexas como aquelas vigentes na indústria cultural. 
Quando o enredo da minissérie é considerado de viés, focalizando especialmente as tramas armadas no entorno da personagem encarnada por Cláudia Abreu, é notável o acionamento de estratégias de alusão, delineando um movimento reflexivo que se volta, sim, para os "papéis" desempenhados pela própria indústria cultural durante o regime militar: os jornalistas e a empresa editorial figurando como instâncias indiretas de remissão à própria televisão. Ao representar o movimento heroico de jornalistas - condensado em Damasceno (não por acaso encarnado pelo icônico Geraldo Del Rey), o honorável militante do "Partidão" e pai de Maria Lúcia -, assumindo as posições de porta-voz da experiência, bem como de resistência pacífica à censura e à repressão políticas como contraponto à luta armada, é forçoso reconhecer, a abordagem joga água no moinho autoapologético apontado por Ismail Xavier.

O mesmo já não se pode afirmar peremptoriamente sobre a figuração da indústria cultural representada pela editora. A empresa de Queiroz (Carlos Zara) - pai de uma das amigas de Maria Lúcia e personificação do ideal missionário de ilustração incensado pelas casas editoriais do período - é abalroada pela censura e pela concentração monopólica que o regime militar incentiva em diversos setores da economia. Gradativamente o editor enfrenta dificuldades financeiras decorrentes das apostas arriscadas pela edificação cultural ou pelo engajamento político e pede socorro ao grupo Andrade Brito, prelúdio da incorporação ao conglomerado empresarial.

Inicialmente o processo se condensa em torno do conflito entre o editor e Edgar, preposto de Fábio na editora, como personificações da legitimidade cultural versus a submissão da inteligência à lógica comercial típica da indústria cultural. Posteriormente a contradança segue com Edgar assumindo a posição ocupada pelo antigo editor contra o comercialismo desbragado representado por Waldir, rapaz pobre - filho do porteiro alcoólatra no prédio onde mora João Alfredo - que, mediante amparo da turma, empenho escolar e cooptação por Fábio (para quem, numa figuração dos procedimentos utilizados pela polícia política, presta serviços de informante), consegue ascender socialmente.

A condenação da indústria cultural como suporte por inteiro do regime militar é figurada pelo desfecho das tramas vinculando as personagens Heloísa, Fábio e o cenário da editora. Waldir descobre o plano para retirar do país João Alfredo, Heloísa e seu companheiro, Marcelo (Rubens Caribé) - com quem tem uma filha (a prole é sinal inequívoco de virtude no melodrama) -, organizado por Maria Lúcia, a essa altura casada com Edgar, tradutora e secretária executiva da editora, e Bernardo (André Barros), irmão de Heloísa. Dividido entre os amigos e o patrão, Waldir revela o plano para Fábio, prova de lealdade e, numa espécie de pacto fáustico, trunfo que lhe permitirá alçar maiores voos no conglomerado. Consequentemente o vilão desbarata o plano, exigindo uma mudança de rota que, na descarga de maior voltagem melodramática da minissérie, termina por acarretar a morte da própria filha numa perseguição deflagrada pela polícia política. 
Únicas a alterar radicalmente as respectivas posições sociais durante a narrativa, os destinos cruzados das personagens de Cláudia Abreu e de André Pimentel lançam luz sobre o condensado caudaloso de experiências plasmado em Anos rebeldes. Por um lado, impulsionada pela identificação visceral com os de baixo - figurada na relação com a personagem Zulmira (Edyr de Castro), mulher negra que a criou e a quem confia a própria filha devido à situação de clandestinidade - e pelo processo de conscientização vivenciado mediante contato com o pessoal do Colégio Pedro II, Heloísa recusa a se submeter ao tráfico de mulheres e sabota o circuito fechado da reprodução social do império comercial que lastreia o poderio do pai (ao mesmo tempo patriarca, proprietário, tirano, arquivilão, enfim), para assumir o martírio de uma trajetória descendente de radicalização voluntarista e comunhão de destino com os condenados da terra. Por outro, espécie de decalque carbonado do subalterno identificado com o opressor e movido a ressentimento de classe, Waldir rompe com a posição de agregado submetido ao favor humilhante da turma, para palmilhar, calçado em investimento escolar, ambição e virtù maquiavélica, a ascensão social irrefragável.

A fatura formal evidencia o peso reconhecível (as tais "marcas autorais") do poder espiritual exercido por Gilberto Braga, de um lado, e do poder temporal empalmado por Dennis Carvalho, de outro. O sobranceiro desprezo pelo agregado arrivista mal esconde as espalhafatosas disposições das frações pequenoburguesas que - tendo desfrutado dos prazeres associados à prolongada inculcação sedimentada pelo investimento escolar (por sua vez, viabilizada por uma origem social privilegiada) - veem o signo da ameaça na mera visibilidade de uma população alquebrada que a fotogenia da Rede Globo, como instância suprema da indústria cultural no Brasil, fracassa em recalcar. ${ }^{24}$ Já o encantamento pela imagem meio sapeca, meio coquete do anjo vingador guarda afinidade com as disposições de outras frações da pequena burguesia obrigadas a renunciar aos prazeres mais "sublimes", "refinados" e "desinteressados" (preconizados pelo arbitrário cultural dominante) em função de uma vida submetida ao trabalho criativo precoce e compulsório demandado pelas instâncias articuladas junto ao núcleo duro do polo ampliado do mercado de bens simbólicos à brasileira. Eis o entroncamento inflamável de tensões e angústias sociais que enforma o funcionamento desempenado da indústria cultural local e seus produtos.

\section{DESFECHO}

De modo geral, a análise sociológica da teleficção produzida pela Rede Globo em particular e dos bens simbólicos radicados no polo ampliado de produção cultural demonstra gume conceitual, ganhos metodológicos e rentabilidade explicativa inequívocos. Para além da acuidade cognoscitiva do conceito de indústria cultural - desde que devidamente desbastado do ranço etnocêntrico e intelectualista, bem como rigorosamente informado historicamente ${ }^{25}-$, o en- 
caminhamento realizado pelo presente trabalho esboça uma abordagem cruzada, apta a apreender os rendimentos econômicos advindos das obras de arte e os mecanismos de legitimação simbólica dos bens culturais produzidos segundo a racionalidade mercantil. O formato minissérie tal como aclimado pela emissora poderia ser tomado, então, como expressão cabal da dinâmica vigente num mercado de bens simbólicos no qual as fronteiras entre os polos restrito e ampliado não se estabeleceram de modo tão demarcado como nos países europeus em que a autonomia dos campos de produção da cultura legítima se firmou muito antes do espraiamento da lógica mercantil para as demais dimensões da vida social (Ridenti, 20I4: 3I-32).

O estabelecimento desse enquadramento exige a rejeição terminante da atitude sobranceira tipicamente etnocêntrica e intelectualista que repõe, sob a aparência de um juízo depreciativo acerca do "des-valor inerente" aos bens simbólicos produzidos no âmbito da indústria cultural - juízo esse que por vezes não passa das favas contadas de um julgamento social do gosto -, a aversão ou mesmo o desprezo de classe pelas pessoas que os consomem. Ao contrário dos estudos que, mediante todo um esforço de investidura, assumem a roupagem de portadores desse tipo de atitude, o presente trabalho quer se alinhar às posições segundo as quais os bens simbólicos oriundos do polo ampliado de produção cultural - mesmo quando simplesmente reciclam fórmulas rotineiras ou deliberadamente legitimam o status quo - têm o princípio de sua ação eficaz atrelado ao trabalho transformador que realizam sobre angústias e tensões sociais com um potencial utópico em certa medida inconforme à ordem:

Reescrever o conceito de uma administração do desejo em termos sociais nos permite pensar o recalque e a satisfação [...] conjuntamente, dentro da unidade de um mecanismo único, que dá e toma igualmente, numa espécie de compromisso ou barganha psíquicos. Isso estrategicamente desperta um conteúdo imaginário no interior de estruturas de contenção cuidadosamente simbólicas que o desarmam, gratificando os desejos intoleráveis, irrealizáveis, propriamente imperecíveis apenas na medida em que possam ser momentaneamente aplacados (Jameson, I995: 25).

Isso - é importante não perder de vista - tanto para o "bem" (existem ordens sociais mais ou menos intoleráveis) quanto para o "mal" (as experiências autoritárias estão aí a assombrar todo e qualquer sonho feliz de sociedade). Seja como for, os produtos da indústria cultural - quer aqueles tomados como os mais degradados do ponto de vista estético, quer aqueles que, mediante toda aversão declarada e cuidados de higiene sanitária, a crítica cultural se digna a examinar - sempre desempenham funções práticas, econômicas, sociais, políticas e culturais insuspeitadas que justificam o esforço de uma análise sociológica. 
Dimitri Pinheiro é graduado em ciências sociais pela Universidade de São Paulo. Possui mestrado e doutorado pelo Programa de PósGraduação em Sociologia da mesma instituição. Realizou estágio sanduíche junto ao Consortium For Women Research da Universidade da Califórnia - Davis. Estuda temas relacionados à história social dos intelectuais e indústria cultural no Brasil, com ênfase em televisão. Integra o Núcleo de Sociologia da Cultura (USP). É autor de "Jogo de damas: trajetórias de mulheres nas ciências sociais paulistas - I934-I969" e coautor, com Alexandre Bergamo, de "Indústria cultural no Brasil e o balanço da sociologia: dois pesos, muitas medidas". 


\section{NOTAS}

I Este artigo resulta de pesquisa realizada junto ao PPGSUSP e contou com apoio da Fapesp. Apresentei versões em 2018 na mesa "A despedida do Ministério da Cultura e artistas em pé de guerra (I989-I990)" do Pequeno Ciclo História da Política Cultural no Brasil (I980-I993), organizado pelo CPF (Sesc-SP), e na quarta sessão do III Seminário Internacional de Sociologia da Cultura (USP). Agradeço nas pessoas de Fábio Marelonka Ferron e de João Victor Kosicki, respectivamente, os comentários suscitados nessas ocasiões. Sou especialmente grato a Luiz Carlos Jackson, que leu, comentou e fez sugestões fundamentais.

2 Para uma discussão sobre a hierarquia simbólica dos objetos nas ciências sociais, ver Pinheiro e Bergamo (2018). Convém mencionar ao menos três dos trabalhos mais importantes para a argumentação relativa a minisséries aqui desenvolvida: Lobo (2000), Kornis (2000) e Xavier (2003). Embora desiguais, as análises realizadas nesses trabalhos têm em comum o enraizamento institucional nas escolas de comunicação, bem como a convergência para Anos rebeldes como ponto de fuga.

3 O termo não é usual. Além de ser uma categoria nativa, a opção por "teledramaturgia" teria a vantagem de evidenciar a influência da experiência teatral na constituição da televisão no Brasil e, adicionalmente, enfatizar sua especificidade em relação ao caso estadunidense, no qual, ao contrário, o cinema é que foi determinante. A opção por "teleficção" se ampara em Xavier (2003), mesmo que o autor não apresente nenhuma justificativa explícita. O rigor que o crítico dispensa à fatura das obras cinematográficas, bem como a própria problematização subjacente à rejeição da categoria estabelecida, indica, entretanto, uma preocupação com a precisão terminológica. Assim como no cinema, os formatos ficcionais audiovisuais produzidos e veiculados pela televisão apresentam traços estilísticos que estão mais distantes da ação dramática e relativamente próximos dos gêneros épicos ou narrativos. Para uma discussão avalizada do problema, ver Rosenfeld (2004: 30-3I).

4 No original, the "period" in question is understood not as some omnipresent and uniform shared style or way of thinking 
and acting, but rather as the sharing of an objective situation, to which a whole range of varied responses and creative innovations is then possible, but always within that situation's structural limits.

5 Inter-relações entre essas formulações podem ser rastreadas em Xavier (2000), Jameson (I992) e Auerbach (I997).

6 Vinte e três telenovelas foram produzidas no mesmo período. Convém mencionar que a elas eram dedicados três horários fixos da grade diária de programação da Rede Globo. Os demais formatos - unitário e seriado - não contaram com produção e exibição rotinizadas no mesmo interregno temporal. Salvo menção em contrário, as informações referentes aos programas foram coligidas no Guia ilustrado TV Globo (2010) ou no sítio eletrônico Memória Globo (c20I3). Tanto a publicação quanto o sítio integraram as iniciativas que celebraram os 45 anos da emissora. Uma descrição sintética do esquema de financiamento para o caso da telenovela é realizada por Borelli (2005). Para uma avaliação em registro prático e comparativo tendo em vista a minissérie, ver Daniel Filho (200I).

7 Sobre a estruturação do domínio televisivo em dois polos de legitimidade, ver Bergamo (2006).

8 Escritas por autores associados à modernização da cena teatral no Brasil - Dias Gomes, Bráulio Pedroso, Jorge de Andrade e, eventualmente, Lauro César Muniz foram escalados para o horário -, as telenovelas que eram veiculadas introduziram efetivamente temas, linguagem e procedimentos narrativos considerados ousados para a televisão. Condizente com autoimagem heroica que construíram de si próprios nesse período, a censura traumática a Roque santeiro é praticamente onipresente nas memórias dos profissionais que trabalharam na emissora. Ver, por exemplo, Daniel Filho (I988), Dias Gomes (I998) e Oliveira Sobrinho (20II).

9 A análise desenvolvida por Sallum Jr. (I996) flagra de modo agudo a ocasião exata em que essa inflexão ocorre. Para relatos que corroboram a importância política da Rede Globo e de seu dono no período, ver, por exemplo, Lima (2005) e Bial (2004).

Io Os rumos tomados inicialmente pelo Globo-Shell Especial e, posteriormente, pelo Globo Repórter são exemplares a 
esse respeito. A participação de cineastas de esquerda nesses programas é discutida por Ridenti (2000). Conti (20I2) resume de modo sintético os processos de centralização e padronização estética do Globo Repórter, bem como a retomada do controle direto do telejornalismo pela família Marinho após a demissão de Walter Clark. Sacramento (20II) estuda minuciosamente os dois projetos de produção que deram origem aos programas. Para uma apresentação oficial de suas diferentes fases, ver o descritor Globo Repórter no sítio Memória Globo (c2013).

II Que a Rede Globo tenha priorizado inicialmente o formato seriado, mais nitidamente especializado se comparado à telenovela e à minissérie, é um evidente indicativo disso. O simples arrolamento dos títulos dos primeiros seriados realizados já demonstra essa conexão: Ciranda cirandinha (1978), voltado para o público jovem com maior escolaridade; Malu mulher (I979-I980), ao feminino com maior escolaridade; Carga pesada (I979-I98I), ao masculino com menor escolaridade; e Plantão de polícia (I979-I98I), masculino com maior escolaridade. Uma caracterização histórica e formal do unitário (single play), seriado (serie) e da minissérie (serial) pode ser conferida em Williams (2003). Para uma discussão mais detalhada, ver Pallottini (20I2). Em registro prático, Daniel Filho (200I) também enfatiza o caráter menos segmentado da telenovela em relação ao seriado. A análise realizada por Almeida (20II) contextualiza e dimensiona o impacto de Malu mulher.

I 2 O projeto também teve colaboração de Antônio Mercado, Ferreira Gullar, Joaquim Assis, Luiz Gleiser, Marília Garcia, Doc Comparato (chefe do Departamento de Formação de Autores) e Euclydes Marinho (responsável pelo Departamento de Novos Formatos). O próprio Dias Gomes (I998) atribuiu o malogro a acusações internas de dirigismo cultural e a uma campanha promovida em veículos impressos e eletrônicos capitaneada pelo jornalista conservador Ferreira Neto. Outras explicações enfatizam a resistência da parte dos autores - principalmente os "tradicionais" -, que teriam visto a tentativa de instaurar processos coletivos de trabalho como uma possível ameaça às prerrogativas colocadas pela posição que ocupam na hierarquia interna de produção televisiva (Ortiz \& Ramos, I99I). 
I3 Sobre isso, ver o item "Curiosidades" no descritor Anos dourados (Memória Globo, c2013).

I4 Ver o item "Driblando a censura" do roteiro publicado em livro - um caso ainda raro - de Anos rebeldes (Braga, 20Io: 29). Diferentemente da versão original, a adaptação da peça $O$ pagador de promessas à linguagem televisiva, realizada pelo próprio Dias Gomes com direção da cineasta Tizuka Yamazaki, tematizou a reforma agrária e denunciou explicitamente o latifúndio. Após a exibição do primeiro capítulo, Roberto Marinho deu ordens para que Boni suspendesse a veiculação. O executivo resistiu, apelando para Roberto Irineu - filho do proprietário e então vice-presidente executivo -, que negociou a exibição mediante o corte de quatro capítulos iniciais da minissérie. Na versão de Boni (Oliveira Sobrinho, 20II: 364-365), o proprietário fora pressionado por amigos. Já segundo Dias Gomes (I998: 340), a reação foi capitaneada pelas lideranças da União Democrática Ruralista e do Banco Bradesco (Ronaldo Cayado e Amador Aguiar, respectivamente). Como é o usual em disputas como essas, a controvérsia ganhou os jornais: autor, executivo e proprietário - num inusitado editorial assinado em O Globo, Roberto Marinho acusa Dias Gomes de trair a própria obra (e, implicitamente, a sua confiança) - trocaram acusações (Cortes na minissérie..., I988: 3I; Quem traiu, I988: I). O embaraço revela, simultaneamente, a margem que o exercício compulsório da criatividade exigido pela indústria cultural concede aos produtores e a distância relativa - no telejornalismo isso praticamente inexiste quer em função da maior familiaridade profissional, quer pela sua imbricação imediata com o campo do poder - da ingerência dos proprietários em relação ao setor de entretenimento. Sobre o caráter compulsório do trabalho criativo demandado pela indústria cultural, ver Miceli (20I8). As constrições impostas pelo campo do poder sobre o telejornalismo em geral podem ser rastreadas em Conti (2012).

I5 A expressão populismo de esquerda se refere à caracterização que faz Schwarz (I992: 63) de uma vertente, predominante no Brasil pré-I964, de socialismo "forte em anti-imperialismo e fraco na propaganda e organização da luta de classes". A tal formulação convém acrescentar 
que a correspondência dessa vertente no plano estético foi o "nacional-popular".

I6 Para uma demonstração tangível de como o contrato com a Rede Globo poderia dificultar a vida profissional, ver o caso de Walter George Durst (Lebert, 2009).

I7 La crème de la crème é a expressão utilizada para se referir às minisséries tanto pelos profissionais quanto por pesquisas que incorporam a classificação nativa (Balogh, 2004). Os depoimentos de profissionais geralmente associam o melhor de suas carreiras na televisão ao trabalho realizado nesses programas teleficcionais.

I8 Ainda que implicitamente, a ênfase conferida às circunstâncias de produção para a análise de minisséries da Rede Globo foi proposta por Kornis (2000). Diferentemente dessa abordagem, entretanto, a reconstituição de tais circunstâncias aqui delineada realiza o trabalho raciocinado de mediação entre as condicionantes gerais, os princípios hierárquicos vigentes na televisão como domínio específico de atividades, os trajetos dos profissionais e as tomadas de posição inscritas na fatura das obras.

I9 Não obstante o decalque da versão heroica recriada pelo próprio Gilberto Braga, bem como da imputação de um sentido unívoco à reação do público, ver a reconstituição circunstanciada do episódio realizada por Ab'Saber (2003).

20 Sobre diferentes expressões da imaginação melodramática, conferir Brooks (I984).

2 I A "parceria" autor-diretor é "estratégica" (Ortiz \& Ramos, I99I: I5I; Hamburger, 2005: 45) na produção de programas televisivos, mormente os de teleficção. Embora menos sujeita à interferência do público - seja mediante dispositivos de sondagem de opinião, seja por meio de veículos impressos e eletrônicos - do que a telenovela, a produção da minissérie também se dá em meio a intrincadas redes de relações entre profissionais em colaboração (Becker, 2008: 43). Não obstante, as posições de "autor" (poder espiritual) e "diretor geral" (poder temporal) exercem maior pressão na definição dos rumos e dos resultados finais das produções específicas na televisão.

22 Embora a experiência de ter assistido a Anos rebeldes quando o programa foi veiculado pela primeira vez tenha in- 
fluído, a análise aqui desenvolvida só foi possível a partir da versão compacta comercializada em Digital Video Disc pela Som Livre (Anos rebeldes, 2003). Em que pese o privilégio de poder preservar parcela considerável da sua própria produção audiovisual pela posição de verdadeiro aparelho que a teleficção da Rede Globo ocupa, não é possível deixar de registrar aqui os obstáculos praticamente intransponíveis colocados aos pesquisadores pelo controle draconiano exercido sobre o próprio acervo- passível de ser contornado muito parcialmente em função do esforço (animado pelo amor comum aos programas de televisão) despendido por colecionadores amadores ou do solidário auxílio prestado pelos funcionários alocados no Centro de Documentação (Cedoc) - nem, tampouco, o holocausto rotineiro a que foi submetida parcela inestimável da cultura audiovisual brasileira decorrente quer da própria orientação para o curto prazo imposta pela lógica mercantil, quer do reaproveitamento cotidiano de videoteipes já gravados, quer, ainda, da simples carência de recursos para sustentar arquivos privados ou da quase inexistência de instituições públicas dedicadas a esse trabalho. Para uma reflexão pioneira sobre esses aspectos no contexto argentino, ver Mestman e Varela (20II).

23 A afirmação é deliberadamente rebarbativa, mas não é possível avançar nesse debate aqui. Sobre os elementos estruturais e, mais precisamente, uma caracterização política do "melodrama clássico", ver Thomasseau (20I2). Para uma análise que considera os desdobramentos mais contemporâneos dessa forma na indústria cultural, ver Xavier (2003). A caracterização do melodrama como democrático se apoia em Brooks (I984).

24 "Atualmente, alguns filmes brasileiros me irritam um pouco. Pobreza com gente feia. Ora, no neorrealismo italiano, em Ladrões de bicicleta o protagonista é um cara atraente [;] Belíssima tem a Anna Magnani. Cidade de Deus, por exemplo, tem atores muito bonitos. Nas produções mais recentes, porém, a miséria e gente muito feia têm sido um osso duro de roer" (Braga, 20Io: 27; grifos meus). Acerca da longa tradição de fotogenia no caso do cinema e do pensamento (social e político) radicados no Brasil, ver Salles Gomes (1973). 
25 Nesse ponto a análise aqui desenvolvida se associa ao esforço despendido pelo melhor da tradição sociológica radicada no Brasil no sentido de aclimar o conceito de indústria cultural. A acepção rigorosa desse conceito "supõe a configuração de um sistema articulado de diferentes meios de produção, difusão e conservação cultural (jornais, editoras, gravadoras, agências de propaganda, emissoras de rádio, canais de televisão, telefonia móvel e, mais recentemente, as diversas plataformas da Internet), cujo financiamento rotineiro depende dos recursos obtidos através da concorrência entre os setores pelos gastos com publicidade" (Pinheiro \& Bergamo, 2018: I07I08). Para formulações nessa direção, ver Cohn (20I4) e Arruda (1985).

\section{REFERÊNCIAS BIBLIOGRÁFICAS}

Ab'Sáber, Tales. (2003). O dia que o Brasil esqueceu. Folha de S. Paulo, Mais!, p.7-8.

Almeida, Heloisa Buarque de. (2014). Pedagogia feminista no formato da teledramaturgia. In: Miceli, Sergio \& Pontes, Heloísa (orgs.). Cultura e sociedade: Brasil e Argentina. São Paulo: Edusp, p. 269-294.

Anos Rebeldes. (2003). Autoria: Gilberto Braga. Direção: Dennis Carvalho. Som Livre. 3 DVDs (680 min.).

Arruda, Maria Arminda do Nascimento. (1985). A embalagem do sistema: a publicidade no capitalismo brasileiro. São Paulo: Livraria Duas Cidades.

Auerbach, Erich. (1997). Figura. São Paulo: Editora Ática. Balogh, Anna Maria. (2004). Minisséries: la crème de la crème da ficção na TV. Revista da USP, 6I, p. 94-IoI.

Becker, Howard S. (2008). Los mundos del arte: sociología del trabajo artístico. Bernal: Universidad Nacional de Quilmes. Bergamo, Alexandre. (2006). Imitação da ordem: as pesquisas sobre televisão no Brasil. Tempo Social, I8/I, p. 303328.

Bial, Pedro. (2004). Roberto Marinho. Rio de Janeiro: Jorge Zahar Ed. (Memória Globo.) 
Borelli, Silvia Helena Simões. (2005). Telenovela: padrão de produção e matrizes populares. In: Brittos, Valério Cruz et al. (orgs.). Rede Globo: 40 anos de poder e hegemonia. São Paulo: Paulus, p. 187-203.

Bourdieu, Pierre. (2005) [1992]. As regras da arte: gênese e estrutura do campo literário. 2 ed. São Paulo: Companhia das Letras.

Braga, Gilberto. (2010). Anos rebeldes: os bastidores de uma minissérie. Rio de Janeiro: Rocco.

Brooks, Peter. (1984). The melodramatic imagination: Balzac, Henry James, melodrama, and the mode of excess. New York: Columbia University Press.

Bucci, Eugênio. (1997). Cultura: maledetto latifúndio. Entrevista concedida a Rogério Scottili e Ricardo Azevedo. Teoria e Debate, 34.

Cohn, Gabriel. (2014). Sociologia da comunicação: teoria e ideologia. Petrópolis: Editora Vozes. (Coleção Sociologia.)

Conti, Mario Sergio. (2012). Notícias do Planalto: a imprensa e o poder nos anos Collor. São Paulo: Companhia das Letras.

Cortes na minissérie foram "ato de rotina", diz Boni. (I988). Folha de S. Paulo, Ilustrada, p. A-3I.

Daniel Filho, João Carlos. (200I). O circo eletrônico: fazendo TV no Brasil. Rio de Janeiro: Jorge Zahar Ed.

Daniel Filho, João Carlos. (1988). Antes que me esqueçam. 4 ed. Rio de Janeiro: Editora Guanabara.

Dias Gomes, Alfredo. (1998). Apenas um subversivo. Rio de Janeiro: Bertrand Brasil.

Hamburger, Esther. (2005). O Brasil antenado: a sociedade da novela. Rio de Janeiro: Jorge Zahar Ed.

Jameson, Fredric. (I995). As marcas do visível. Rio de Janeiro: Graal.

Jameson, Fredric. (1992). The geopolitical aesthetic: cinema and space in the world system. Bloomington: Indiana University Press.

Jameson, Fredric. (1988). Peridizing the 6os. In: Ideologies of theory: essays I97I-I986. V. 2. The syntax of history. London/Minneapolis: Routledge/University of Minnesota Press, p. I78-208. 
Kornis, Mônica Almeida. (2000). Uma história do Brasil recente nas minisséries da Rede Globo. Tese de Doutorado. PPGCom/Universidade de São Paulo.

Lebert, Nilu. (2009). Walter George Durst: doce guerreiro. São Paulo: Imprensa Oficial do Estado de São Paulo. (Coleção Aplauso.)

Lima, Venício A. de. (2005). Globo e política: tudo a ver. In: Brittos, Valério Cruz et al. (orgs.). Rede Globo: 40 anos de poder e hegemonia. São Paulo: Paulus, p. I03-I29.

Lobo, Narciso Júlio Freire. (200o). Ficção e política: o Brasil das minisséries. Manaus: Ed. Valer.

Memória Globo. (c2013). Disponível em <http://memoriaglobo.globo.com>. Acesso em 9 dez. 2018.

Memória Globo. (2010). Guia ilustrado TV Globo: novelas e minisséries. Rio de Janeiro: Jorge Zahar Ed.

Mestman, Mariano \& Varela, Mirta. (20II). Televisión: 60 años de historia sin archivos. ReHiMe: Cadernos de la rede de historia de los médios, I, p.I40-I83.

Miceli, Sergio. (2018). Sonhos da periferia: inteligência argentina e mecenato privado. São Paulo: Todavia.

Oliveira Sobrinho, Bonifácio. (20I I). O liuro do Boni. Rio de Janeiro: Casa da palavra.

Ortiz, Renato \& Ramos, José Mário Ortiz. (I99I) [I989]. A produção industrial e cultural da telenovela. In: Ortiz, Renato et al. Telenovela: história e produção. São Paulo: Brasiliense, p. III-I82.

Pallottinni, Renata. (2012). Dramaturgia de televisão. 2 ed. São Paulo: Perspectiva.

Pinheiro, Dimitri \& Bergamo, Alexandre. (20I8). Indústria cultural no Brasil e o balanço da sociologia: dois pesos, muitas medidas. In: Miceli, Sergio \& Martins, Carlos Benedito. (orgs.). Sociologia brasileira hoje II. Cotia: Ateliê Editorial.

Quem traiu. (I988). O Globo, p.I.

Ridenti, Marcelo. (20I4). Caleidoscópio da cultura brasileira (1964-2000). In: Miceli, Sergio \& Pontes, Heloisa (orgs.). Cultura e sociedade: Brasil e Argentina. São Paulo: Edusp, p. 2I-7I. 
Ridenti, Marcelo. (2000). Em busca do povo brasileiro: artistas da revolução, do CPC à era da tu. Rio de Janeiro: Editora Record.

Rosenfeld, Anatol. (2004). O teatro épico. São Paulo: Editora Perspectiva.

Sacramento, Igor. (20II). Depois da revolução, a televisão: cineastas de esquerda no jornalismo televisivo dos anos I970. São Carlos: Pedro \& João Editores.

Salles Gomes, Paulo Emílio. (1973). Cinema: trajetória no subdesenvolvimento. Rio de Janeiro: Paz e Terra/Embrafilme. Sallum Jr., Brasilio. (I996). Labirintos: dos generais à Nova República. São Paulo: Hucitec.

Schwarz, Roberto. (I992) [I978]. Cultura e política, I96469. In: Pai de família e outros estudos. Rio de Janeiro: Editora Paz e Terra, p. 6I-92.

Thomasseau, Jean-Marie. (2012). O melodrama. São Paulo: Perspectiva.

Xavier, Ismail. (2003). O olhar e a cena. São Paulo: Cosac \& Naify.

Xavier, Ismail. (2000). O cinema brasileiro dos anos 90. Praga, 8, p. 97-I38.

Williams, Raymond. (2003). Television: technology and cultural form. London/New York: Routledge. 


\section{ANOS REBELDES E A ABERTURA DA TELEFICÇÃO}

Resumo

O artigo aborda Anos rebeldes, minissérie da Rede Globo de Televisão veiculada entre junho e agosto de I992. Primeira incursão explícita da teleficção da emissora pelo tema regime militar, a exibição do programa coincide com um momento decisivo no processo de democratização política do país: a campanha Fora Collor. A análise delineia telegraficamente as condicionantes gerais, as circunstâncias de produção e o enredo da minissérie, enfatizando uma vertente de suas tramas. O objetivo é examinar diferentes figurações da indústria cultural na teleficção brasileira com rebatimentos reflexivos sobre a própria atitude dos estudos em relação ao objeto. Longe dos juízos depreciativos acerca do "des-valor inerente" aos bens simbólicos associados ao polo ampliado de produção cultural, o argumento sustentado aqui é o de que tais objetos sempre desempenham funções práticas, econômicas, sociais, políticas e culturais insuspeitadas que justificam o esforço de uma análise sociológica.

\section{ANOS REBELDES AND THE OPENING OF THE} TV SERIAL DRAMA

\footnotetext{
Abstract

The article approaches Rebel Years, a serial of Rede Globo Television that was displayed between June and August of I992. It was the first time that the television station explicitly approached the theme of the military regime, and the show's presentation happened at a decisive moment in the process of political democratization of the country: the campaign for "Fora Collor" (Collor Out). The analysis slightly outlines the general conditions, the circumstances of production and the plot of the miniseries, giving emphasis in one specific story. Its objective is to examine different representations of the cultural industry in the Brazilian telefiction with a reflexive repercussion about the attitude of academic studies themselves in relation to the object. Far from the disparaging judgments about the "inherent worthlessness" of symbolic goods associated with the expanded pole of cultural production, the argument advanced here is that such objects always perform unsus pected practical, economic, social, political, and cultural functions that justify the effort of a sociological analysis.
}

Palavras-chave

televisão;

teleficção;

minissérie;

figura.

Keywords

Cultural industry;

television;

telefiction;

serial;

figure. 